Int. J. Electrochem. Sci., 15 (2020) 8041 - 8054

\title{
N, S co-doped Graphene/Ag@Au Triangular Core-Shell Nanomaterials for Determination of Quercetin
}

\author{
Shaoping Feng ${ }^{1,2,3}$, Jiale Guo ${ }^{1,2}$, Xianlan Chen ${ }^{1,2, *}$, Jinming Meng ${ }^{1,2, *}$, Guowei Zhang ${ }^{1,2, *}$, \\ Guiyang Liu ${ }^{1,2}$, Hongyan Sun ${ }^{1,2}$, Baosen Wang ${ }^{1,2}$, Wei Liu ${ }^{1,2}$ \\ ${ }^{1}$ College of Science, Honghe University, Mengzi, 661199, Yunnan, P.R.China \\ ${ }^{2}$ Local Characteristic Resource Utilization and New Materials Key Laboratory of Universities in \\ Yunnan, Honghe University, Mengzi, 661199, Yunnan, China \\ ${ }^{3}$ School of Metallurgical and Ecological Engineering, University of Science and Technology Beijing, \\ Beijing 100083, China \\ *E-mail: 13489086418@163.com,352603936@qq.com, yunnmzh@126.com
}

doi: $10.20964 / 2020.08 .44$

Received: 21 March 2020 / Accepted: 16 May 2020 / Published: 10 July 2020

In the study, a hydrothermal method was used to prepare N, S co-doped graphene (NS-G) with graphenes oxide $(\mathrm{GO})$ as raw material, L-cysteine $\left(\mathrm{C}_{3} \mathrm{H}_{7} \mathrm{NO}_{2} \mathrm{~S}\right)$ as sulfur source, nitrogen source and reductant. The atoms of $\mathrm{N}$ and $\mathrm{S}$ have been completely bonded to carbon atoms when the mass ratio of GO and L-cystein was 1:5. Then, the NS-G was impregnated with Ag@Au triangular core-shell nanomaterials (T-Ag@Au NPs) prepared by seed-mediated growth method to obtain N, S co-doped graphene/Ag@Au triangular core-shell nanomaterials (NS-G/T-Ag@Au NPs). The NS-G/T-Ag@Au NPs were dropped on glassy carbon electrode (GCE) to construct a novel modified electrode (NS-G/T$\mathrm{Ag} @ \mathrm{Au}$ NPs/GCE) for sensing quercetin. The electrochemical sensor for quercetin determination exhibited excellent stability and sensitivity with a good linear range $(0.5 \mu \mathrm{M}-15.0 \mu \mathrm{M})$ and low the detection limits $\left(5 \times 10^{-8} \mathrm{M}\right)$. The NS-G/T-Ag@Au NPs/GCE, in particular, was successfully applied for determination of quercetin in tea and honeysuckle samples with desirable recovery range (97.46$103.48 \%$ ) and relative standard deviation (RSD, 1.27-5.10\%).

Keywords: N, S co-doped graphene; T-Ag@Au NPs; Quercetin; Electrochemical sensor

\section{$\underline{\text { FULL TEXT }}$}

(C) 2020 The Authors. Published by ESG (www.electrochemsci.org). This article is an open access article distributed under the terms and conditions of the Creative Commons Attribution license (http://creativecommons.org/licenses/by/4.0/). 